Research Paper

\title{
Risk Factors for Major Adverse Events of Video-Assisted Thoracic Surgery Lobectomy for Lung Cancer
}

Jie Yang*, Yan Xia*, Yang Yang, Zheng-zheng Ni, Wen-xin He, Hai-feng Wang, Xiao-xiong Xu, Yu-ling Yang, Ke Fei ${ }^{\bowtie}$, Ge-ning Jiang ${ }^{\bowtie}$

Department of Thoracic Surgery, Shanghai Pulmonary Hospital, Tongji University School of Medicine, Shanghai, 200433, China

* Dr. Jie Yang and Yan Xia contribute equally to this work.

$\triangle$ Corresponding authors: Dr. Jiang, 507 Zhengmin Road, Shanghai 200433, China. E-mail: jgnwp@aliyun.com. Ke Fei, Lung Cancer Institute, Shanghai Pulmonary Hospital, Tongji University School of Medicine, Shanghai 20043, China; ffeik@126.com

(1) Ivyspring International Publisher. This is an open-access article distributed under the terms of the Creative Commons License (http://creativecommons.org/ licenses/by-nc-nd/3.0/). Reproduction is permitted for personal, noncommercial use, provided that the article is in whole, unmodified, and properly cited.

Received: 2014.02.24; Accepted: 2014.05.29; Published: 2014.06.II

\begin{abstract}
Aims: The purpose of this study was to identify the risk factors for major adverse events of VATS (Video-Assisted Thoracic Surgery) lobectomy for primary lung cancer.

Methods: 1806 Patients (1032 males, 57.1\%) planned to undergo VATS lobectomy for stage IA-IIIA lung cancer from July 2007 to June 20I2. The Thoracic Morbidity and Mortality Classification TM\&M system was used to evaluate the presence and severity of complications. Postoperative complications were observed during a 30-day follow up. Univariate and multivariate analysis were used to analyze the independent risk factors for major adverse events.

Results: Successful rate of VATS lobectomy was $97.6 \%$ (I763/I806). Major complications occurred in 129 patients $(7.3 \%)$, with a mortality of $0.3 \%$ (5/I763). Pulmonary complications contribute up to $90.7 \%$ of the major complications and $80 \%$ of mortality. Logistic regression indicated that comorbidities, elder age $\geq 70 y$, operative time $\geq 240 \mathrm{~min}$ and hybrid VATS were predictors for major adverse events $(P<0.05)$. Hybrid and converted VATS lobectomy result in higher major adverse events compared with complete VATS, $15.1 \%, 20.9 \%$ and $7.4 \%$ respectively $(\mathrm{P}=0.013)$.

Conclusions: The overall complication rate and mortality of VATS lobectomy are low, while major complications sometimes occur. Pulmonary complications are the most common major complications and cause of mortality. Age $\geq 70 y$, comorbidities, operative time $\geq 240 \mathrm{~min}$ and Hybrid VATS are predictors of major adverse events.
\end{abstract}

Key words: Non-small cell lung cancer, VATS, Lobectomy, Major Adverse Events, Risk factor

\section{Introduction}

With the widespread use of early screening tools such as multi-slice spiral computed tomography (CT) and positron emission tomography (PET), more and more early staged lung cancers have been detected and treated with surgery. As a minimal invasive operation, video-assisted thoracic surgery (VATS) has been more and more widely used for the treatment of lung cancer. But indications for the VATS lobectomy vary for different surgeons. How to choose surgical approach still remains a problem for marginal cases.

Although complications of VATS lobectomy are at a low level, there is still certain degree of complications and mortality for the procedure ${ }^{1-5}$. Besides, currently, most of published studies have only taken the presence of complications into account, without concern of the severity, making the conclusion less objective. It is of great importance to make an objective and accurate evaluation and identify the risk factors of 
complications. In this retrospective analysis, we use the TM\&M system to grade complications and investigated predictors for major complications and mortality after VATS lobectomy for primary lung cancer ${ }^{6,7}$.

\section{Patients and Methods}

\section{Patients}

The study was approved by the ethics committee of Shanghai Pulmonary Hospital. A total of 1806 consecutive patients underwent VATS lobectomy for stage IA-IIIA primary lung cancer between July 2007 and June 2012 in our department. All patients received thorough examinations including abdominal ultrasonography or CT scan, whole-body radionuclide bone scanning, PET-CT and head CT or magnetic resonance imaging (MRI) to exclude distant metastasis. Mediastinoscope or endobronchial ultrasound-guided transbronchial needle aspiration (EBUS-TBNA) was performed when chest CT scan indicated N3 diseases.

Indications for VATS lobectomy included: no ipsilateral thoracotomy history; no evidence of severe pleural adhesions; resectable lesions $\leq 5 \mathrm{~cm}$; no clinical sign of multiple N2 metastases. Surgeon experience and preference were also relative indications. Preoperative discussion of each case was mandatory. All patients' clinical data were presented to evaluate the safety and efficiency at the routine meetings every Tuesday and Friday morning. The leading group made up of 4 most experienced surgeons in our department would authority the surgery and applicable approach.

This series included consecutive patients whom preoperative intention was to resect with VATS procedure. Exclusion criteria included: Patients with a history of neoadjuvant chemotherapy or radiotherapy, procedures other than lobectomy, such as wedge, segmentectomy, bilobectomy, pneumonectomy, or chest wall resection. All patients were restaged according to the 7th edition of TNM classification.

\section{VATS Technique}

Under general anesthesia, double-lumen endotracheal intubation with selective contralateral lung ventilation was achieved. A 30 degree high definition thoracoscope was recommended. 3 ports were used for most of the operations. Complete VATS lobectomy was defined as finishing the whole procedure using only the vision of a monitor and without rib spreading. Surgery employing direct version or rib distractor was defined as Hybrid VATS. Complete VATS was applied in most cases, hybrid VATS or conversion to thoracotomy were performed whenever the perfor- mance of complete VATS was considered to be challenging.

Aspirator, electrocautery, electrotome or long scissor was used to separate lung tissue up to surgeon's preference. Staples were used to divide vein, fissures and bronchus. Staples or silk ligature were used to divide artery. After completion of lobectomy, specimen retrieval was performed using an endoscopic retrieval bag. The patients would undergo systematic mediastinal lymph node dissection if the frozen section indicated malignant.

\section{Complication and Classification}

A complication was defined as any deviation from normal postoperative course. Perioperative mortality was defined as death during the same hospitalization as surgery or within 30 days after the procedure. All the complications were graded according to TM\&M system (Table 1), in which the complication grade of individuals was evaluated according to the most severe complication of each patient. Grade I and II complications were defined as minor complications, grade III and IV were defined as major complications, and grade $\mathrm{V}$ was mortality. Major complications and mortality were described as major adverse events. The Common Terminology Criteria for Adverse Events (version 4.03) published by National Institute of Health was also used to refine a number of definitions 8 .

Table I. TM\&M Classification of Complications for Thoracic Surgery

\begin{tabular}{|c|c|}
\hline Grade & Definition \\
\hline Complication & Any deviation from the normal postoperative course \\
\hline \multicolumn{2}{|l|}{ Minor } \\
\hline Grade I & $\begin{array}{l}\text { Any complication without need for pharmacologic treat- } \\
\text { ment or other intervention }\end{array}$ \\
\hline Grade II & $\begin{array}{l}\text { Any complication that requires pharmacologic treatment } \\
\text { or minor intervention only }\end{array}$ \\
\hline \multicolumn{2}{|r|}{ 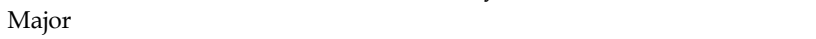 } \\
\hline Grade III & $\begin{array}{l}\text { Any complication that requires surgical, radiologic, en- } \\
\text { doscopic intervention, or multitherapy }\end{array}$ \\
\hline IIIa & Intervention does not require general anesthesia \\
\hline $\mathrm{IIIb}$ & Intervention requires general anesthesia \\
\hline Grade IV & $\begin{array}{l}\text { Any complication requiring intensive care unit manage- } \\
\text { ment and life support }\end{array}$ \\
\hline IVa & Single organ dysfunction \\
\hline $\mathrm{IVb}$ & Multiorgan dysfunction \\
\hline \multicolumn{2}{|l|}{ Mortality } \\
\hline Grade V & Any complication leading to the death of the patient \\
\hline
\end{tabular}

\section{Data Collection}

Preoperative protocols were obtained from the medical history. Operation database was reviewed and all relevant information was collected in detail. 
Patient's general information, findings on auxiliary examinations, comorbidities, and pathological diagnosis were collected.

Variables recorded included age, sex, smoking, body mass index (BMI), comorbidities, predicted FEV1\% (forced expiratory volume in 1 second, FEV1), tumor size, nodal status, and histologic characteristics. Comorbidities included coronary artery disease, hypertension, cerebral vascular event, chronic obstructive pulmonary disease, chronic renal insufficiency, and diabetes mellitus. One pack year of smoking would mean that someone had smoked one package of cigarettes (20 cigarettes) daily for one year.

\section{Statistical Analysis}

SPSS 18.0 software (SPSS Inc, Chicago, IL) was used for the data analysis. $\chi^{2}$ test was used to compare categorical variables; $t$ test and non-parametric test were used to compare continuous variables. For predictors of complications, univariate analysis was applied for possible variables that may influence complications. A multivariable logistic analysis was then performed using variables with a univariate $P$ value less than 0.1 . And a $P$ value of less than 0.05 was considered to indicate statistical significance.

\section{Results}

\section{Patient Characteristics}

Among 1806 patients, 1763 patients with a mean age of $(59.1 \pm 10.5)$ years (range from 19 to 89$)$ underwent VATS lobectomy successfully. The mean operative time was $(181 \pm 57) \mathrm{min}$, with an estimated blood loss of $(206 \pm 352) \mathrm{ml}$. Nearly $90 \%$ of procedures could be finished in less than $240 \mathrm{~min}$ with less than $600 \mathrm{ml}$ blood loss. Patient characteristics are shown in table 2 . These patients were eligible for analysis of risk factors for major adverse events. Conversion cases were not included when analyzing risk factors of VATS lobectomy.

\section{Complications and Risk Factors}

A total of 451 complications occurred in 316 patients (17.9\%). Major and mortality accounted for $34.6 \%$ of all complications. Grade II complications made up the majority of complications with a proportion of $61.2 \%$. The most common complications included prolonged air leak, arrhythmia, pulmonary atelectasis, and pleural effusion. Pulmonary complications accounted for $59.6 \%$ of all complications, $43.4 \%$ of minor, $90.7 \%$ of major and $80 \%$ of mortality respectively. Minor-only complications occurred in 182 patients $(10.3 \%)$ and major complications occurred in 129 patients (7.3\%). No intraoperative deaths occurred. There were 5 postoperative deaths
$(0.3 \%)$. Details of the complications are shown in table 3.

Table 2. Patient Characteristics

\begin{tabular}{|c|c|c|}
\hline Variable & $\mathbf{N}$ & $\%$ \\
\hline \multicolumn{3}{|l|}{ Age (y) } \\
\hline$\geq 70$ & 322 & 18.3 \\
\hline$<70$ & 1441 & 81.7 \\
\hline \multicolumn{3}{|l|}{ Gender } \\
\hline Male & 1007 & 57.1 \\
\hline Female & 756 & 42.9 \\
\hline \multicolumn{3}{|l|}{ Pack year of Smoking } \\
\hline$\geq 20$ & 507 & 28.8 \\
\hline$<20$ & 1256 & 71.2 \\
\hline \multicolumn{3}{|l|}{ BMI $\left(\mathrm{kg} / \mathrm{m}^{2}\right)$} \\
\hline$>28$ & 129 & 7.3 \\
\hline $18-28$ & 1587 & 90.0 \\
\hline$<18$ & 47 & 2.7 \\
\hline \multicolumn{3}{|l|}{ Location of tumor } \\
\hline Left Upper Lobe & 427 & 24.2 \\
\hline Left Lower Lobe & 306 & 17.4 \\
\hline Right Upper Lobe & 520 & 29.5 \\
\hline Right Middle Lobe & 154 & 8.7 \\
\hline Right Lower Lobe & 356 & 20.2 \\
\hline \multicolumn{3}{|l|}{ Comorbidities } \\
\hline Yes & 393 & 22.3 \\
\hline No & 1370 & 77.7 \\
\hline \multicolumn{3}{|l|}{ FEV1\% } \\
\hline$\geq 50$ & 1716 & 97.3 \\
\hline$<50$ & 47 & 2.7 \\
\hline \multicolumn{3}{|l|}{ TNM staging } \\
\hline IA & 611 & 34.7 \\
\hline IB & 752 & 42.7 \\
\hline IIA & 118 & 6.7 \\
\hline IIB & 28 & 1.6 \\
\hline IIIA & 254 & 14.4 \\
\hline \multicolumn{3}{|l|}{ Tumor size $(\mathrm{cm})$} \\
\hline$\geq 3$ & 1062 & 60.2 \\
\hline$<3$ & 701 & 39.8 \\
\hline \multicolumn{3}{|l|}{$\mathrm{N}$ status } \\
\hline No & 1395 & 79.1 \\
\hline N1 & 134 & 7.6 \\
\hline N2 & 234 & 13.3 \\
\hline \multicolumn{3}{|l|}{ Histology } \\
\hline Adenocarcinoma & 857 & 48.6 \\
\hline Squamous carcinoma & 170 & 9.6 \\
\hline Others & 420 & 23.8 \\
\hline \multicolumn{3}{|l|}{ Type of VATS } \\
\hline Complete & 1710 & 97.0 \\
\hline Hybrid & 53 & 3.0 \\
\hline \multicolumn{3}{|l|}{ Number of ports } \\
\hline 3 & 1423 & 80.7 \\
\hline 4 & 340 & 19.3 \\
\hline \multicolumn{3}{|l|}{ Operative time (min) } \\
\hline$\geq 240$ & 189 & 10.7 \\
\hline$<240$ & 1574 & 89.3 \\
\hline \multicolumn{3}{|l|}{ Blood loss (ml) } \\
\hline$\geq 600$ & 225 & 12.8 \\
\hline$<600$ & 1538 & 87.2 \\
\hline
\end{tabular}


Table 3. Complications of Patients after VATS Lobectomy

\begin{tabular}{|c|c|c|}
\hline Complication Grade & $\mathbf{N}$ & $\%$ \\
\hline Grade I & 19 & 4.2 \\
\hline Pulmonary & 8 & 1.8 \\
\hline Pneumothorax (cured without intervention) & 8 & 1.8 \\
\hline Other & 11 & 2.4 \\
\hline Urine tract infection (only need to remove urine tube) & 8 & 1.8 \\
\hline Delirium & 3 & 0.7 \\
\hline Grade II & 276 & 61.2 \\
\hline Pulmonary & 120 & 26.6 \\
\hline Prolonged air leak & 68 & 15.1 \\
\hline Pneumonia & 22 & 4.9 \\
\hline Atelectasis & 14 & 3.1 \\
\hline Chylothorax $(\leq 200 \mathrm{ml} / 24 \mathrm{~h}$, need fat free diet $)$ & 8 & 1.8 \\
\hline Subcutaneous emphysema (modification of chest tube position) & 8 & 1.8 \\
\hline Other & 156 & 34.6 \\
\hline Arrhythmia (AF, PVC etc.) & 85 & 18.8 \\
\hline Hypertension (need intravenously drip antihypertensive drugs) & 27 & 6.0 \\
\hline Anemia (need transfusion) & 23 & 5.1 \\
\hline Coagulation disorders & 7 & 1.6 \\
\hline Peptic ulcer & 5 & 1.1 \\
\hline Urine tract infection & 4 & 0.9 \\
\hline Abdominal pain & 3 & 0.7 \\
\hline Delirium (need sedative) & 2 & 0.4 \\
\hline Grade IIIa & 99 & 22.0 \\
\hline Pulmonary & 93 & 20.6 \\
\hline Atelectasis (need sputum suction) & 42 & 9.3 \\
\hline Pleural effusion (need thoracentesis) & 43 & 9.5 \\
\hline Subcutaneous emphysema (need chest tube reinsertion) & 4 & 0.9 \\
\hline Chylothorax (need fasting and TPN) & 4 & 0.9 \\
\hline Other & 6 & 1.3 \\
\hline Heart failure & 6 & 1.3 \\
\hline Grade IIIb & 13 & 2.9 \\
\hline Pulmonary & 13 & 2.9 \\
\hline Pleural bleeding & 4 & 0.9 \\
\hline Lung torsion & 2 & 0.4 \\
\hline Bronchopleural fistula & 5 & 1.1 \\
\hline Chylothorax (need operation) & 2 & 0.4 \\
\hline Other & 0 & 0.0 \\
\hline Grade IVa & 37 & 8.2 \\
\hline Pulmonary & 29 & 6.4 \\
\hline ARDS & 12 & 2.7 \\
\hline Severe pneumonia & 7 & 1.6 \\
\hline Pulmonary embolism & 10 & 2.2 \\
\hline Other & 8 & 1.8 \\
\hline Cerebrovascular events & 3 & 0.7 \\
\hline Heart failure (need ICU management) & 5 & 1.1 \\
\hline Grade IVb & 2 & 0.4 \\
\hline Pulmonary & 2 & 0.4 \\
\hline ARDS combined with heart failure & 2 & 0.4 \\
\hline Other & 0 & 0.0 \\
\hline Grade V & 5 & 1.1 \\
\hline Pulmonary & 4 & 0.9 \\
\hline Pulmonary embolism & 2 & 0.4 \\
\hline Severe pneumonia combined with ARDS & 2 & 0.4 \\
\hline Other & 1 & 0.2 \\
\hline Sepsis, septic shock, multiple organ failure & 1 & 0.2 \\
\hline Total complications & 451 & 100 \\
\hline Total patients with complications & 316 & 17.9 \\
\hline
\end{tabular}

Variables with a $P$ value $<0.1$ in univariate analysis were selected for multivariate logistic regression, in terms of age, gender, pack year of smoking, comorbidities, FEV1\%, TNM stage, tumor size, operative time, blood loss, histology and types of VATS.
Multivariate logistic regression analysis showed that comorbidities (OR=1.764, 95\% Cl: 1.164-2.673, $P=0.007)$, elder age $\geq 70 \mathrm{y} \quad(\mathrm{OR}=2.919, \quad 95 \% \mathrm{CI}$ : 1.932-4.409 $P<0.001$ ), and long operative time $\geq 240 \mathrm{~min}$ $(\mathrm{OR}=2.440,95 \% \mathrm{CI}: 1.467-4.057, P=0.001)$ and hybrid VATS (OR=2.868, 95\%CI: 1.278-6.437, $P=0.011)$ were independent risk factors for major adverse events. The results are summarized in table 4 .

Table 4. Predictors for Major Adverse Events after VATS lobectomy

\begin{tabular}{|c|c|c|c|c|}
\hline \multirow[b]{2}{*}{ Variable } & \multirow[b]{2}{*}{$\mathbf{N}$} & \multirow{2}{*}{$\begin{array}{l}\text { Univariate } \\
P \text { Value }\end{array}$} & \multicolumn{2}{|c|}{ Multivariate } \\
\hline & & & OR $(95 \%$ CI) & $P$ Value \\
\hline Age, y & & $<0.001$ & $2.919(1.932-4.409)$ & $<0.001$ \\
\hline$\geq 70$ & 48 & & & \\
\hline$<70$ & 86 & & & \\
\hline Gender & & 0.014 & $1.183(0.741-1.888)$ & 0.482 \\
\hline Male & 90 & & & \\
\hline Female & 44 & & & \\
\hline Pack year of Smoking & & 0.002 & $1.399(0.900-2.713)$ & 0.136 \\
\hline$\geq 20$ & 54 & & & \\
\hline$<20$ & 80 & & & \\
\hline BMI $\left(\mathrm{kg} / \mathrm{m}^{2}\right)$ & & 0.062 & $1.408(0.822-2.413)$ & 0.213 \\
\hline$>28$ & 18 & & & \\
\hline $18-28$ & 105 & & & \\
\hline$<18$ & 11 & & & \\
\hline Location of Tumor & & 0.326 & & \\
\hline Left Upper Lobe & 25 & & & \\
\hline Left Lower Lobe & 26 & & & \\
\hline Right Upper Lobe & 42 & & & \\
\hline Right Middle Lobe & 14 & & & \\
\hline Right Lower Lobe & 27 & & & \\
\hline Comorbidities & & $<0.001$ & $1.764(1.164-2.673)$ & 0.007 \\
\hline Yes & 49 & & & \\
\hline No & 85 & & & \\
\hline FEV1\% & & 0.001 & $1.899(0.841-4.290)$ & 0.123 \\
\hline$\geq 50$ & 124 & & & \\
\hline$<50$ & 10 & & & \\
\hline TNM stage & & 0.006 & $1.085(0.934-1.262)$ & 0.286 \\
\hline IA & 32 & & & \\
\hline IB & 65 & & & \\
\hline IIA & 7 & & & \\
\hline IIB & 2 & & & \\
\hline IIIA & 28 & & & \\
\hline Tumor size $(\mathrm{cm})$ & & 0.038 & $1.395(0.890-2.186)$ & 0.147 \\
\hline$\geq 3$ & 92 & & & \\
\hline$<3$ & 42 & & & \\
\hline Nodal status & & 0.252 & & \\
\hline No & 101 & & & \\
\hline N1 & 9 & & & \\
\hline $\mathrm{N} 2$ & 24 & & & \\
\hline Histology & & 0.089 & $0.952(0.739-1.227)$ & 0.705 \\
\hline Adenocarcinoma & 84 & & & \\
\hline Squamous carcinoma & 31 & & & \\
\hline Others & 19 & & & \\
\hline Type of VATS & & 0.023 & $2.868(1.278-6.437)$ & 0.011 \\
\hline Complete & 126 & & & \\
\hline Hybrid & 8 & & & \\
\hline Number of ports & & 0.209 & & \\
\hline 3 & & & & \\
\hline 4 & & & & \\
\hline Operative time (min) & & $<0.001$ & $2.440(1.467-4.057)$ & 0.001 \\
\hline$\geq 240$ & 27 & & & \\
\hline$<240$ & 107 & & & \\
\hline Blood loss (ml) & & 0.072 & $0.987(0.588-1.654)$ & 0.959 \\
\hline$\geq 600$ & 25 & & & \\
\hline$<600$ & 109 & & & \\
\hline
\end{tabular}




\section{Conversion Patients}

$43(2.4 \%)$ cases were converted to thoracotomy for the following reasons: uncontrolled bleeding in 7 , severe adhesions in 24, sleeve resection in 5, chest wall invasion in 3, vascular invasion in 4 cases. Severe adhesion was the main cause of conversion. The overall postoperative complication rate was $39.5 \%$, and major adverse events occurred in $16.3 \%$ in conversion patients.

Comparison of complete, hybrid VATS and converted lobectomy groups showed that elder age $\geq 70 \mathrm{y}$ and comorbidities were similar, but the operative time of $240 \mathrm{~min}$ and major adverse events were significantly higher in hybrid and converted group $(P<0.001$ and $P=0.013$ respectively). (Table 5)

Table 5. Compare of Hybrid, Complete VATS and Conversion Lobectomy

\begin{tabular}{lllll}
\hline & Hybrid & \multicolumn{2}{l}{ Conversion Complete } & \\
\hline Variable & $\mathbf{( N = 5 3 )}$ & $\mathbf{( N = 4 3 )}$ & $\mathbf{( N = 1 7 1 0 )}$ & P value \\
\hline Age y $\geq 70$ & $11(20.8 \%)$ & $8(18.6 \%)$ & $311(18.2 \%)$ & 0.893 \\
Comorbidities & $14(26.4 \%)$ & $11(25.6 \%)$ & $379(22.2 \%)$ & 0.739 \\
Operative time $\geq 240 \mathrm{~min}$ & $8(15.1 \%)$ & $14(35.0 \%)$ & $181(10.6)$ & $<0.001$ \\
Complications & $20(37.7 \%)$ & $19(44.2 \%)$ & $297(17.4)$ & $<0.001$ \\
Major adverse events & $8(15.1 \%)$ & $9(20.9 \%)$ & $126(7.4 \%)$ & 0.013 \\
\hline
\end{tabular}

\section{Discussion}

Since first described in 1990s, VATS lobectomy has been gradually adopted in general thoracic surgery. The Society of Thoracic Surgeons database demonstrates $44.7 \%$ of pulmonary resections were performed by VATS in $2010{ }^{9}$. In the latest 2013 guidelines of the NCCN, VATS lobectomy has been considered as a reasonable and acceptable approach for NSCLC, with no compromise of standard oncologic or dissection principles of thoracic surgery ${ }^{10}$.

Many studies have suggested that VATS lobectomy is superior to thoracotomy with less intraoperative blood loss, reduced hospital length of stay, decreased postoperative pain, better treatment compliance, low postoperative complications, better postoperative pulmonary function, similar operative time, and equal long-term outcomes, and VATS lobectomy had a complication rate of $6-34.2 \%$ and mortality of $0.6-1.3 \%$ 1-5,11-15. But grading of complications was not mentioned in most studies. Common Terminology Criteria for Adverse Events (CTCAE) was used in some studies, but it was not specific for thoracic surgery. In our study, according to the TM\&M system, major adverse events were in acceptable level and the majority of them were pulmonary complications.

There were $5(0.3 \%)$ operative mortalities in our series, and complications of any kind occurred in
$17.9 \%$ of patients in this study, which is much lower than the $32 \%$ complication rate $(2.5 \%$ mortality $)$ among 9033 pulmonary resections for primary lung cancer reported in a STS database study ${ }^{16}$. The favorable results in this group may be related to high selection of patients and rich experience of postoperative care. On the other hand, the major complication rate was $7.6 \%$ compared with a Composite major morbidity rate of $7.9 \%$ among 18,800 lung cancer resections $(65.5 \%$ lobectomy) performed at 111 participating centers ${ }^{17}$. These results indicate that minimally invasive approaches reduce overall perioperative complications, but have less effect on major complication. A reasonable explanation is that extent of resection is the most important determinant of major complication.

Operative time is a very important element impacting complications. Haraguchi used receiver-operator characteristics curves to analyze the risk factors of VATS. Results showed that surgery lasting more than 297 min offset the advantages of VATS and if the duration of surgery would be more than five hours for any reason, conversion to limited thoracotomy or muscle-sparing methods was recommended18. Our study showed most VATS lobectomy could be finished in $240 \mathrm{~min}$, and long operative time $\geq 240$ min was independent risk factor for major adverse events. The result suggested that duration of operation has a significant influence on postoperative complications. $240 \mathrm{~min}$ could be a potential reference for the time to convert. Surgeons could estimate the time needed to complete the operation according to their experience. If the estimated time exceeds 240 min, the surgeon should consider conversion earlier. Meanwhile, we found the same result (i.e., the incidence of major complications in patients with duration of operation over $240 \mathrm{~min}$ is significantly higher than that of those with duration of operation under $240 \mathrm{~min}$ ) in patients who have higher operation difficulty and need to convert to Hybrid VATS. The result suggested that it is beneficial for the patients to convert to Hybrid VATS earlier if the operation can hard to complete VATS. Additionally, duration of operation over 240 min could be served as a predictive factor for postoperative major complications. Such Patients may need more intensive care and early intervention. So surgeons should be more careful when selecting patients for the procedure, especially during learning curve. Conversion should be considered if operative time is too long.

It is reported that VATS lobectomy for clinical stage I non-small cell lung cancer in the elderly (age $\geq 70 \mathrm{y})$ was associated with fewer $(28 \%$ vs. $45 \%$; P < $0.05)$ and overall reduced severity of complications compared with thoracotomy ${ }^{19}$. In another study, oc- 
togenarians undergoing video assisted major pulmonary resection had a higher incidence of atrial fibrillation and admission to the intensive care unit for cardiopulmonary support but otherwise were not different from younger age groups in the conversion rate, morbidity or mortality ${ }^{20}$. This might be associated with the fact that the institute was at the beginning of VATS program and the complications of both groups were at high levels. Our study showed that elder age was independent risk factors for major complications.

VATS lobectomy was considered to be a feasible and safe procedure for selected patients even with comorbidities ${ }^{21,22}$. But our study showed that comorbidities were also independent risk factor for major adverse events. So we should always be aware of patients with comorbidities and a prolonged postoperative care is recommended.

Poor preoperative pulmonary function has been a well-recognized predictor for morbidity and mortality after lung cancer surgery, and a preoperative FEV1\% of greater than $50 \%$ has been recommended for patients receiving lung resection ${ }^{23}$. Video-assisted thoracic surgery pulmonary resection for cancer in patients with poor lung function could achieve acceptable functional and oncologic outcome ${ }^{24}$. A STS database analysis concluded that poor pulmonary function predicted respiratory complications regardless of approach and respiratory complications increased at a significantly greater rate in patients with poor pulmonary function after thoracotomy lobectomy compared with VATS ${ }^{9}$. In our study, poor preoperative pulmonary function was not the predictor for major adverse events. It might result from our high selection of patients.

Complete VATS were feasible in most patients. According to our results, hybrid VATS was an independent risk factor for major adverse events. It might be due to the fact that hybrid VATS was performed during the procedure that the surgery would be too difficult without such extension, which resulted in increasing operative time and major adverse events. Conversion to thoracotomy was applied in even more difficult cases. Conversion was reported to occur in 1.6-23\% of patients ${ }^{4,25-28}$. Converted VATS caused increased length of surgery, chest tube duration and estimated blood loss when compared with planned thoracotomy 29. Tumor and pleural conditions are main cause for conversion. Preoperative thorough evaluation to choose the proper approach and conversion to thoracotomy immediately when necessary are recommended. Severe intraoperative complications are other reasons for conversion. Liang et al reported that severe intraoperative complications during VATS lobectomy were manageable, and at a low incidence similar to open lobectomy ${ }^{30}$. Surgeons need to take proper caution in performing VATS lobectomy.

In conclusion, we find that the overall complication rate and mortality of VATS lobectomy are low, while there is still significant incidence of major complications. Pulmonary complications are most common major complications and main cause of mortality. Elder age $\geq 70 y$, comorbidities, operative time $\geq 240 \mathrm{~min}$ and hybrid VATS are predictors for major adverse events. Hybrid VATS and converted lobectomy result in significant higher major adverse events, so we need to be more careful when selecting patients. If inevitable, an early conversion to Hybrid VATS or thoracotomy is recommended.

The main limitations of this study are the retrospective nature of the study and lack of randomization. There is certainly a degree of bias in patient selection and surgeon experience. The lack of patients in subgroup may cause the failure of finding of effect of pulmonary function on major complications. How some variables such as severity of comorbidities affect complication rate was not discussed because of lack of data. Further prospective randomized controlled trials are needed to confirm these findings.

\section{Acknowledgement}

The authors would like to thank Shanghai Hospital Development Center Grant for the support of this study (Grant No.shdc12012111).

\section{Competing Interests}

The authors have declared that no competing interest exists.

\section{References}

1. Solaini L, Prusciano F, Bagioni P, et al. Video-assisted thoracic surgery (VATS) of the lung: analysis of intraoperative and postoperative complications over 15 years and review of the literature. Surg Endosc 2008; 22:298-310

2. Park JS, Kim K, Choi MS, et al. Video-Assisted Thoracic Surgery (VATS) Lobectomy for Pathologic Stage I Non-Small Cell Lung Cancer: A Comparative Study with Thoracotomy Lobectomy. Korean J Thorac Cardiovasc Surg 2011; 44:32-38

3. Kim K, Kim HK, Park JS, et al. Video-assisted thoracic surgery lobectomy: single institutional experience with 704 cases. Ann Thorac Surg 2010; 89:S2118-2122

4. McKenna RJ, Jr., Houck W, Fuller CB. Video-assisted thoracic surgery lobectomy: experience with 1,100 cases. Ann Thorac Surg 2006; 81:421-425; discussion $425-426$

5. Whitson BA, Groth SS, Duval SJ, et al. Surgery for early-stage non-small cell lung cancer: a systematic review of the video-assisted thoracoscopic surgery versus thoracotomy approaches to lobectomy. Ann Thorac Surg 2008; 86:2008-2016; discussion 2016-2008

6. Seely AJ, Ivanovic J, Threader J, et al. Systematic classification of morbidity and mortality after thoracic surgery. Ann Thorac Surg 2010; 90:936-942; discussion 942

7. Ivanovic J, Al-Hussaini A, Al-Shehab D, et al. Evaluating the reliability and reproducibility of the Ottawa Thoracic Morbidity and Mortality classification system. Ann Thorac Surg 2011; 91:387-393

8. [Internet] The Common Terminology Criteria for Adverse Events (CTCAE version 4.03). http://evs.nci.nih.gov/ftp1/CTCAE/About.html.

9. Ceppa DP, Kosinski AS, Berry MF, et al. Thoracoscopic lobectomy has increasing benefit in patients with poor pulmonary function: a Society of Thoracic Surgeons Database analysis. Ann Surg 2012; 256:487-493 
10. [Internet] National Cancer Comprehensive Newtwork. 2013 NCCN Guidelines Version 2.2013 Non-Small Cell Lung Cancer. http://www.nccn.org/professionals/physician_gls/f_guidelines.asp\#nscl.

11. Whitson BA, Andrade RS, Boettcher A, et al. Video-assisted thoracoscopic surgery is more favorable than thoracotomy for resection of clinical stage I non-small cell lung cancer. Ann Thorac Surg 2007; 83:1965-1970

12. Shigemura N, Akashi A, Funaki S, et al. Long-term outcomes after a variety of video-assisted thoracoscopic lobectomy approaches for clinical stage IA lung cancer: a multi-institutional study. J Thorac Cardiovasc Surg 2006; 132:507-512

13. Muraoka $\mathrm{M}, \mathrm{Oka} \mathrm{T}, \mathrm{Akamine} \mathrm{S}$, et al. Video-assisted thoracic surgery lobectomy reduces the morbidity after surgery for stage I non-small cell lung cancer. Jpn J Thorac Cardiovasc Surg 2006; 54:49-55

14. Yamamoto K, Ohsumi A, Kojima F, et al. Long-term survival after video-assisted thoracic surgery lobectomy for primary lung cancer. Ann Thorac Surg 2010; 89:353-359

15. Yan TD, Black D, Bannon PG, et al. Systematic review and meta-analysis of randomized and nonrandomized trials on safety and efficacy of video-assisted thoracic surgery lobectomy for early-stage non-small-cell lung cancer. J Clin Oncol 2009; 27:2553-2562

16. Boffa DJ, Allen MS, Grab JD, et al. Data from The Society of Thoracic Surgeons General Thoracic Surgery database: the surgical management of primary lung tumors. J Thorac Cardiovasc Surg 2008; 135:247-254

17. Kozower BD, Sheng S, O'Brien SM, et al. STS database risk models: predictors of mortality and major morbidity for lung cancer resection. Ann Thorac Surg 2010; 90:875-881; discussion 881-873

18. Haraguchi S, Koizumi K, Hatori N, et al. Postoperative respiratory complications of video-assisted thoracic surgery for lung cancer. J Nippon Med Sch 2004; 71:30-34

19. Cattaneo SM, Park BJ, Wilton AS, et al. Use of video-assisted thoracic surgery for lobectomy in the elderly results in fewer complications. Ann Thorac Surg 2008; 85:231-235; discussion 235-236

20. Amer $\mathrm{K}, \mathrm{Khan} \mathrm{AZ}, \mathrm{Vohra} \mathrm{H}$, et al. Is it safe to include octogenarians at the start of a video-assisted thoracic surgery lobectomy programme? Eur J Cardiothorac Surg 2012; 41:346-352

21. Matsuoka K, Kuroda A, Kang A, et al. Video-assisted thoracoscopic surgery for lung cancer in patients on hemodialysis. Ann Thorac Cardiovasc Surg 2013; 19:263-267

22. Nakanishi $R$, Nakagawa $M$, Tokufuchi $H$, et al. Video-assisted thoracoscopic lobectomy for clinical stage I non-small cell lung cancer: experience with 111 consecutive patients demonstrating comorbidity. Minerva Chir 2012; 67:67-75

23. Markos J, Mullan BP, Hillman DR, et al. Preoperative assessment as a predictor of mortality and morbidity after lung resection. Am Rev Respir Dis 1989; 139:902-910

24. Garzon JC, Ng CS, Sihoe AD, et al. Video-assisted thoracic surgery pulmonary resection for lung cancer in patients with poor lung function. Ann Thorac Surg 2006; 81:1996-2003

25. Roviaro G, Varoli F, Vergani C, et al. Video-assisted thoracoscopic major pulmonary resections: technical aspects, personal series of 259 patients, and review of the literature. Surg Endosc 2004; 18:1551-1558

26. Flores RM, Alam N. Video-assisted thoracic surgery lobectomy (VATS), open thoracotomy, and the robot for lung cancer. Ann Thorac Surg 2008; 85:S710-715

27. Onaitis MW, Petersen RP, Balderson SS, et al. Thoracoscopic lobectomy is a safe and versatile procedure: experience with 500 consecutive patients. Ann Surg 2006; 244:420-425

28. Nicastri DG, Wisnivesky JP, Litle VR, et al. Thoracoscopic lobectomy: report on safety, discharge independence, pain, and chemotherapy tolerance. J Thorac Cardiovasc Surg 2008; 135:642-647

29. Samson P, Guitron J, Reed MF, et al. Predictors of conversion to thoracotomy for video-assisted thoracoscopic lobectomy: a retrospective analysis and the influence of computed tomography-based calcification assessment. J Thorac Cardiovasc Surg 2013; 145:1512-1518

30. Liang C, Wen H, Guo Y, et al. Severe intraoperative complications during VATS Lobectomy compared with thoracotomy lobectomy for early stage non-small cell lung cancer. J Thorac Dis 2013; 5:513-517 